\title{
Uso do moodle no processo de ensino-aprendizagem da disciplina de climatologia zootécnica
}

the moodle usage in the process of teaching-learning of the discipline husbandry climatology

\author{
Sandro Luis Petter Medeiros', Liziany Müller², Andriéli Hedlund Bandeira ${ }^{3}$ \\ I Professor do Departamento de Fitotecnia/CCR/UFSM, E-mail:slpmedeiros@yahoo.com.br \\ 2 Professora do Centro de Ciências Rurais/UFSM, E-mail: lizianym@hotmail.com \\ 3 Doutoranda no Programa de Pós-Graduação em Agronomia/UFSM, E-mail: andrieli_hedlund@hotmail.com
}

\begin{abstract}
Resumo
Existe grande evolução dos artefatos tecnológicos, notadamente, o surgimento de novas tecnologias e as denominadas redes sociais. Por sua vez, os jovens, dentre os quais os estudantes, apresentam grande fascínio pela tecnologia. Essa atração pelo novo, também poder ser usada no processo de ensino aprendizagem através de inovações no modo de lecionar, como por exemplo, o uso da Tecnologias de Informação e Comunicação (TIC). Assim, o referido trabalho busca uma mediação pedagógica mais atrativa e interativa, com uso de Ambientes Virtuais de Ensino e Aprendizagem (AVEA), no processo de ensino-aprendizagem aos estudantes da disciplina de Climatologia Zootécnica do curso de Zootecnia do Centro de Ciências Rurais da UFSM. Também foi caracterizado o perfil e letramento eletrônico do público alvo. Possuem letramento eletrônico adequada para desenvolver atividades no AVEA. Apresentam ótima aceitabilidade para a execução de atividade a distância, pois efetivamente executaram a atividade, com um índice de postagem de $77 \%$. Consideram que atividade as atividades à distância sejam um complemento muito importante daquelas presenciais.
\end{abstract}

Palavras Chave: TIC, Tecnologia Educional, Ensino-Aprendizagem

\begin{abstract}
There is a great evolution of technological artifacts, notably the emergence of new technologies and the so-called social networks. In turn, young people, among them students, have great fascination for technology. This new attraction, it can also be used in the teaching and learning process through innovations in the mode of teaching, such as the use of Information and Communication Technologies (ICT). Thus, the work seeks to formalize a pedagogical mediation more attractive and interactive, using Virtual Environments for Teaching and Learning, for the process of teaching and learning for students of the discipline of Climatology Zootechnical the course of Animal Husbandry Science Center Rural UFSM. It was also characterized the profile and audience of electronic literacy. They have to develop appropriate electronic literacy activities in AVEA. Have great acceptability for running the distance activity because the activity performed effectively, with an index of posting $77 \%$. They consider that the activity distance activities are a very important complement those classroom.
\end{abstract}

Keywords: ICT, Educacional Tecnology, Teaching and learning 


\section{INTRODUÇÃO}

Existe uma grande atração dos jovens pelas tecnologias, dentre as quais se destaca a internet, com considerável participação nas chamadas redes sociais. Nessas tais redes, existem espaços para discussões/comentários sobre fatos ocorridos e postagem de fotos/opiniões, entre outras. Assim, fica evidente que os jovens possuem certa fluência tecnológica, favorecida principalmente pelo acesso facilitado a computadores e celulares.

Os seres humanos mediam sua atividade através de artefatos: o carpinteiro usa um martelo para suas atividades diárias se completarem, as enfermeiras usam o idioma e seus registros para coordenar as ações para os pacientes. As ferramentas são formas de dividir o trabalho. Normas, idiomas e ferramentas (martelo) são vistas como artefatos para a realização da atividade. Os artefatos são feitos pelo homem e servem para mediar às relações entre seres humanos ou entre as pessoas e o material ou produto em fases diferentes entre as pessoas e o material ou produto em fases diferentes (RODRIGUES, 2005).

Existem "artefatos tecnológicos" que são bastante difundidos, principalmente celulares e computadores, e em menor grau, "ipod" e "tablet". Esses equipamentos que até pouco tempo atrás eram manuseados por um pequeno número de pessoas, atualmente se popularizaram, fazendo parte do cotidiano dos indivíduos, como no caso dos estudantes universitários. Como conseqüência, ocorreu maior exposição das atividades humanas, visto que qualquer informação pode ser compartilhada instantânea e mundialmente, fazendo as barreiras de tempo e espaço praticamente não existam.

Os avanços tecnológicos no que tange a equipamentos eletrônicos também foram verificados em sala de aula, onde ferramentas tradicionais de suporte didático como o quadro-negro, foram substituídas pelos retroprojetores e após multimídia, ou seja, passou-se do giz ao "laser point". Apesar da adoção de novos equipamentos/artefatos para fins didáticos, coloca-se a questão: também ocorreu uma evolução do professor no processo de ensino/ aprendizagem ou ainda continuamos no "método tradicional" caracterizado pelo professor (ator) e estudantes (espectadores), ou seja, utilizamos novos artefatos para mediar a mesma relação professor/ estudante do tempo do giz.

Entende-se, conforme, Rodrigues (2005), que a prática do professor não deve postular apenas a transmissão, tendo de um lado o transmissor (professor) e, de outro, o receptor (aluno), mas sim deve levar ao "aprender a aprender", ou seja, deve proporcionar a formação de um sujeito participativo no trabalho, produtivo, não-reprodutivo, consciente de seus atos. Enfoca-se, portanto, para esta pesquisa, a prática pedagógica da metodologia progressista denominada de "tecnologia inovadora"

Ainda nesse contexto, deve-se destacar a posição de Moraes e Varela (2006), os quais mencionam que o uso das tecnologias por si só não caracterizam mudança pedagógica, quando usadas somente como suporte tecnológico para fins de ilustrar a aula. Torna-se torna necessário que as tecnologias sejam utilizadas como mediação da aprendizagem para incrementar o processo ensino-aprendizagem.

A modificação do processo de ensino-aprendizagem passa por uma (r)evolução da postura pedagógica do professor, marcada pela passagem de um educador/transmissor para educador problematizador. Mion et al. (1999) procuram relatar e analisar a construção, na prática, uma formação do educador problematizador e dialógico em Física na perspectiva de instrumentalizá-lo a pensar a própria prática e torná-lo um investigador ativo. A adoção dessa concepção de trabalho advém da conviç̧ão de que não vamos construir projetos emancipatórios sem transformar a dinâmica ação-reflexão, pois, não é possível trabalhar a emancipação sem codificação/descodificação. Para tal é, fundamental, refletir sempre em torno da ação. Isto significa que uma capacidade de aprendizagem é associada ao processo de investigação, como possibilidade de desenvolver a capacidade de pensar por si mesmos, estudar as próprias práticas criticamente, desenvolvendo a compreensão que se tem sobre a mesma, ampliando inclusive, a capacidade de questionar. Enfim, desenvolver-se profissionalmente. Portanto, por meio do processo reflexivo muda-se a concepção de docente, uma vez que, investigando a prática educacional, torna-se investigador ativo e/ ou educador-educando (MION et al. 1999, p. 203-204).

O compromisso com as questões educacionais tem sido ampliado, através das várias formas de organização, incluindo aquelas que fazem uso da tecnologia para superar os limites de espaços e tempos, de modo a propiciar que as pessoas de diferentes idades, classes sociais e regiões tenham acesso à informação e possam vivenciar diversas maneiras de representar o conhecimento. O termo tecnologia envolve o conhecimento técnico e científico, onde ferramentas, processos e materiais são criados e/ou utilizados a partir deste conhecimento (VASCONCELOS; TOGNI, 2011, p. 40).

A Tecnologia na Educação permite novas 
formas de ensinar e aprender, envolvendo mudanças no paradigma de conhecimento de uma sociedade, o qual se caracteriza pelos princípios da diversidade, da integração e da complexidade (VASCONCELOS; TOGNI, 2011, p. 40).

Encontra-se em Muller et al. (2011) que as tecnologias da informação e comunicação são tecnologias da inteligência, por serem novas ferramentas cognitivas que possibilitam um salto qualitativo em nossas possibilidades de raciocínio e apreensão de conhecimento. No cotidiano, a integração das Tecnologias de Informação e Comunicação (TIC) criou novas formas de interação entre as pessoas, que implicaram no redimensionamento das funções e dos papéis sociais.

O recurso digital é, em essência, voltado à ação do usuário, diferentemente das mídias anteriores, expositivas, como o rádio e a televisão. Assim, permite-lhe escolher um caminho, navegar pelo material e ler o conteúdo na ordem em que desejar como se escrevesse seu próprio texto. Essa característica é adequada às práticas educacionais, já que a posição ativa do aluno contribui para a construção do conhecimento (PASSOS; BEHAR, 2011).

A proposta de objetos de aprendizagem vem surgindo justamente para amenizar problemas, facilitando o reaproveitamento de materiais didáticos existentes e a criação de cursos online. Estes objetos podem ser entendidos como pequenos componentes educacionais que podem ser usados em diferentes contextos de aprendizagem. São exemplos de objetos de aprendizagem, vídeos, imagens, aplicativos pequenos, figuras, gráficos e apresentações de slides, além de outros elementos digitais que possibilitam ao aluno adquirir conhecimento enquanto interage com eles. Esses objetos podem incluir conteúdo em multimídia, conteúdo instrucional, objetivo de aprendizagem, software instrucional e software de apoio (VASCONCELOS; TOGNI, 2011).

Com o desenvolvimento das TIC para internet, voltadas ao campo educacional, observa-se a ocorrência de alterações significativas nas interações e na interatividade no processo de ensino e aprendizagem. Devido a esse fator, houve um grande aumento no número de cursos, tanto na modalidade presencial 1 quanto na distância 2 que estão sendo mediados por Ambientes Virtuais de Ensino e Aprendizagem (AVEA). Dessa forma, a interação mediada por computador entre professor e estudantes acontece, quando ambos estão conectados à internet no endereço eletrônico do AVEA, o que permite a comunicação entre os participantes em torno dos materiais e das atividades da disciplina do curso (FRUET; DE BASTOS, 2010, p. 82).

Essa comunicação no âmbito do ensinar-aprender pode ocorrer de duas maneiras: assíncrona e síncrona. A primeira não implica uma interação simultânea. Percebe-se que essa é o modo predominante, uma vez que o aluno, ao ler um material disponibilizado pelo professor na tela do computador ou ao realizar uma atividade agendada pelo docente no AVEA, e o professor, ao ler a respectiva resposta e enviar um feedback, estarão interagindo assincronamente. O correio eletrônico (mensagens), o fórum e o wiki são exemplos de ferramentas que possibilitam comunicação assíncrona. A segunda maneira, síncrona, caracteriza-se por uma interação simultânea, que pode acontecer, por exemplo, por meio da ferramenta chat (FRUET; DE BASTOS, 2010).

Para fins de crescimento individual do estudante, seria interessante aliar essa habilidade e atração dos jovens pela internet, fazendo com que eles também tivessem contato com textos/ conteúdos/vídeos que contribuíssem construtivamente para a sua formação acadêmica. Essa atração dos jovens por "novidades" pode fazer com que o "modelo tradicional" de aula torne-se menos atrativo. Nesse sentido, a utilização de hipermídias torna-se uma ferramenta para útil para incentivar o processo de ensino-aprendizagem dos estudantes ao longo da sua formação acadêmica. Assim, o referido trabalho busca a formalização de uma mediação pedagógica mais atrativa e interativa, com uso de AVEA, para o processo de ensino-aprendizagem aos estudantes da disciplina de Climatologia Zootécnica do curso de Zootecnia do Centro de Ciências Rurais da UFSM. Para isto, também foi necessário caracterizar o perfil e letramento eletrônico do público alvo.

\section{MATERIAL E MÉTODOS:}

O trabalho foi dividido em quatro etapas, detalhadas a seguir com atividades executadas em cada uma delas:

\section{Etapa: Planejamento}

Foi efetuada a capacitação do docente para atuação do TIC/AVEA, com a participação e finalização dos cursos referente Capacitação em Produção de Recursos Educacionais e Capacitação em notas das atividades no Moodle, oferecidos pelo 
Núcleo de Tecnologia Educacional da /UFSM (NTE/UFSM). Esta foi uma etapa preparatória relacionada alfabetização técnica-científica que auxiliou no desenvolvimento das etapas posteriores, pois conforme Mion et al. (1999):

"É nesta direção que trabalhamos a formação e prática do educador problematizador. Com pretensão e possibilidades de tornarmo-nos investigadores ativos empreendemos nossa luta e, portanto, alimentamos nossas esperanças, uma vez que nos propomos investigar nossas próprias práticas educacionais e, portanto, transformar as mesmas a partir do planejamento da ação concreta, construindo, desta maneira, propostas educacionais vinculadas ao conhecimento acumulado e simultaneamente a conhecimentos novos. Uma prática problematizadora que envolve tanto educandos que estarão iniciando-se no processo de alfabetização técnica-científica, quanto a formação de educadores via investigação, pois, estarão investigando suas próprias práticas educacionais e nesse sentido buscando se apropriar do conhecimento elaborado (MION et al. 1999. p. 203-204)."

Concomitante, foi efetuada uma pesquisa sobre objetos educacionais relacionados ao programa da disciplina com o objetivo de encontrar materiais didáticos diferenciados que problematizassem os conteúdos desenvolvidos nas atividades presenciais. Foi escolhido o objeto educacional disponível no site http://www.planetseed.com/ pt-br/node/15879, por apresentar um material que contemplou os objetivos pretendidos na disciplina e também, por ser interativo.

\section{$2^{\mathrm{a}}$ Etapa: Ação e observação}

Foi criada uma página WEB da Climatologia Zootécnica, com auxilio dos recursos oferecidos NTE e CPD/UFSM, sendo colocada a disposição dos estudantes da disciplina a fim de interação, interatividade e colaboração através dos usos dos recursos como hipertexto, hipermídia e artigos (inseridos no Moodle através dos recursos página web e link a um arquivo ou site).

Nesta etapa, houve uma reorganização dos recursos e, principalmente, do número das atividades planejadas. $\mathrm{Na}$ realidade, planejava-se a execução de quatro atividades, porém duas delas não foram executadas e as restantes foram agrupadas em uma única atividade. Essa reorganização foi necessária, pois não foi encontrado um material didático que contemplasse adequadamente $o$ conteúdo de "Clima e Tempo" e de "Temperatura do Ar", conforme o programa da disciplina. As atividades que seriam propostas nos conteúdos "Relação Terra-Sol" e "Radiação Solar" foram englobadas em uma única atividade. Tal decisão, esta relacionada à execução dos cursos de capacitação que propiciariam adquirir habilidades para execução de recursos/atividades no Moodle, as quais evidenciaram que melhor seria executá-las de forma conjunta em virtude do dos assuntos estarem inter-relacionados.

A seguir foi proposta a "Atividade 1", para mediar a atividade de ensino a distância, o professor optou pela "Atividade offline" com envio de arquivo único. Foi dado um prazo de envio, desde 27 de novembro de 2012 até o dia 08 de dezembro de 2012. Também foi disponibilizado um tutorial a fim de orientar a execução da "Atividade 1".

Somente 40 estudantes enviaram a tarefa de um total de 52 matriculados na disciplina. Dos estudantes que enviaram o material, 37 postaram o arquivo via Moodle, enquanto que 3 enviaram via email, pois alegaram terem tido problema com o manuseio da plataforma.

\section{$3^{a}$. Etapa: Avaliação e replanejamento}

$\mathrm{Na}$ Avaliação foi aplicado um questionário avaliativo tipo survey que teve três finalidades principais: a) conhecer o perfil dos estudantes (idade, sexo,...), b) identificar o letramento eletrônico dos estudantes e c) fornecerem subsídio para continuidade/melhoria da mediação pedagógico proposta a fim de detectar dificuldades e desafios enfrentados.

\section{$4^{\mathrm{a}}$. Replanejamento:}

$\mathrm{Na}$ sub-etapa de replanejamento foi efetuada análise dos resultados, contraponto os problemas enfrentados e os benefícios conseguidos a fim de avaliar a continuidade da nova mediação pedagógica na disciplina e/ou modificações a serem propostas.

\section{RESULTADOS E DISCUSSÃO}

Observa-se na Figura 1a que não existe uma predominância entre sexo masculino e feminino dentre os estudantes da disciplina de Climatologia Zootécnica. Com relação à distribuição etária, a Figura $1 b$ evidencia que os estudantes são predominantemente jovens, concentrando ao redor $45 \%$ na faixa de 19 a 22 anos, porém cerca de $10 \%$ 

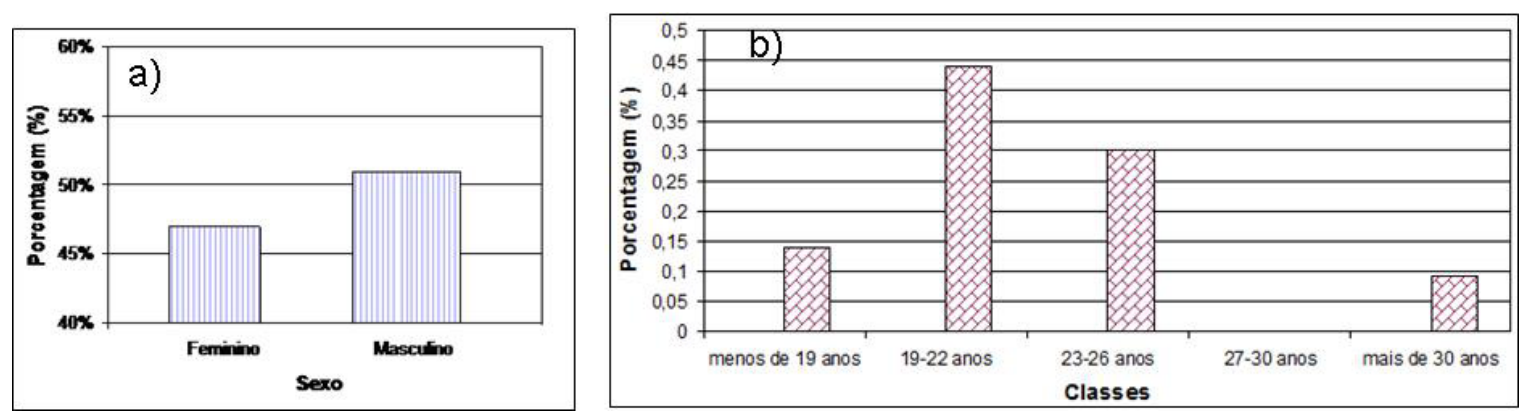

Figura 1 - Caracterização quanto ao sexo (a) e idade (b) dos estudantes da disciplina de Climatologia Zootécnica.

possui no mínimo 30 anos

Analisando-se a freqüência de acessos, constata-se que a maioria dos estudantes possui o hábito de diariamente acessar a internet (Figura 2), sendo que no mínimo acessam duas vezes por semana. Esta resposta índica que os estudantes possuem conhecimento mínimo necessário, ou seja, um letramento eletrônico suficiente para serem estimulados para a utilização de AVEA.

Necessariamente, o uso de AVEA envolve a utilização de um equipamento eletrônico, com maior freqüência implica no uso do computador. Fato que implica em um conhecimento mínimo de procedimentos operacionais para efetuar a mediação. Neste contexto, Buzato (2001) menciona que:

"Poderíamos adotar, por exemplo, um conceito mais radical segundo o qual o analfabeto tecnológico" ou "iletrado tecnológico" é aquele indivíduo que não dispõe do conhecimento técnico para programar computadores. Contudo, sabemos hoje que os computadores não requerem programação por parte do usuário para que possam ser usado no processo de interação social via textos. Não podemos ignorar entanto que o uso do computador para estes fins sócio-educativos é infinitamente mais complexo do que o uso do livro impresso, já que a demanda que o individuo tenha um conhecimento prévio sobre os diferentes sistemas operacionais, e diferentes programas específicos que funcionam como agentes mediadores entre usuário de máquina. Esta mediação entre leitor e texto, é por excelência, um fator que distingue letramento eletrônico do letramento tradicional. Mais especificamente, no caso do texto impresso a mediação entre o leitor e o texto envolve basicamente a operação mecânica de folhar. Já no caso do letramento eletrônico, essa mediação envolve não apenas operações mais mecânicas muitas vezes mais complexas de que folhar, como também dispositivos e programas que o leitor precisa acionar para ter acesso ao texto. Como cada programa executa esta tarefa de maneira particular, é necessário que o leitor domine o programa, ao menos parcialmente antes mesmo que possa ser exposto ao texto que potencialmente lhe apresentará a informação. A chave

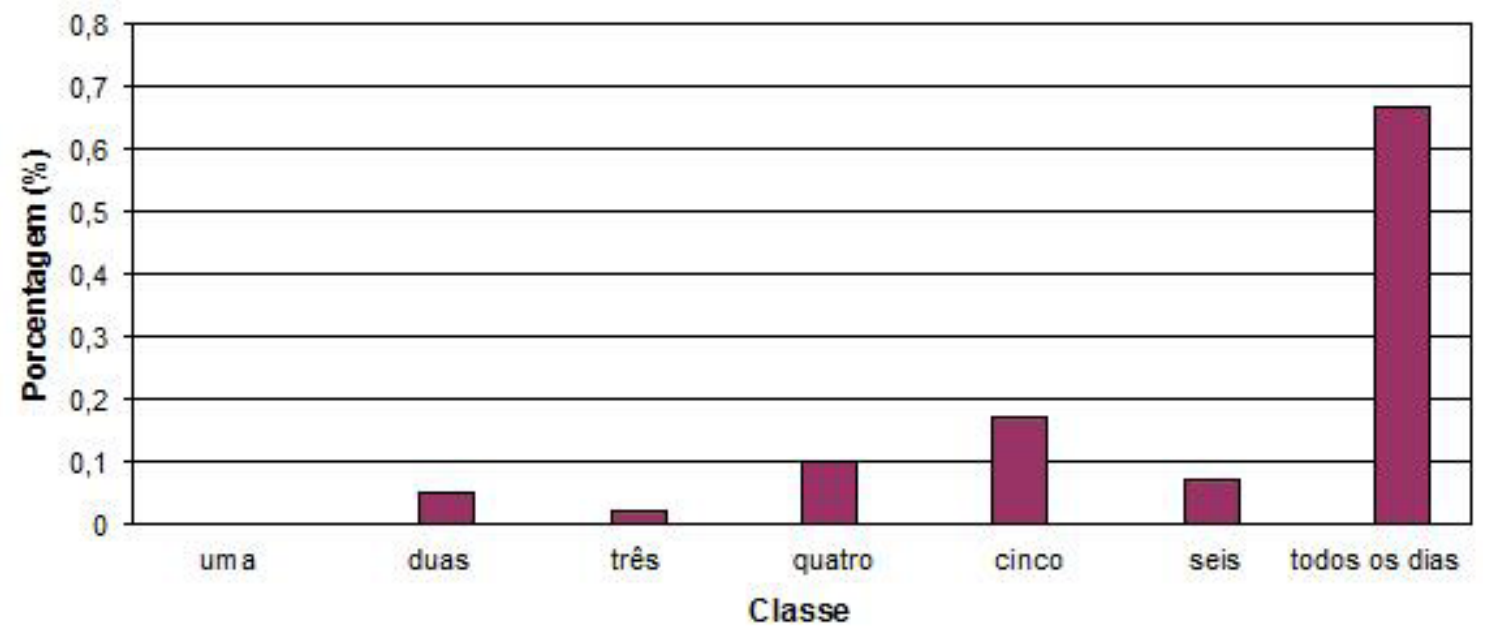

Figura 2 - Frequência de acesso a internet estudantes da disciplina de Climatologia Zootécnica. 


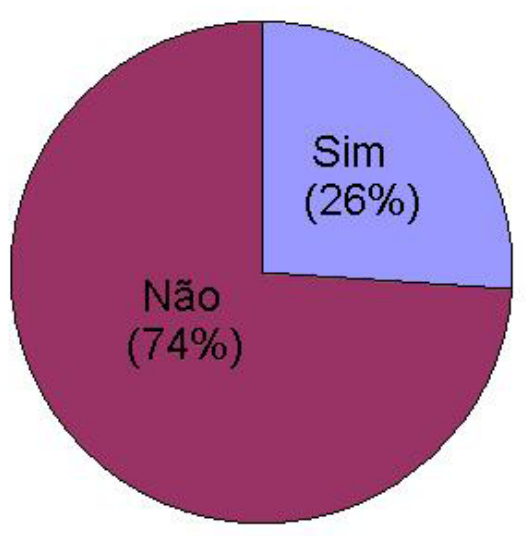

Figura 3 - Utilização prévia de Ambientes Virtuais de Ensino e Aprendizagem dos estudantes da disciplina de Climatologia Zootécnica.

para o domínio de cada um desses programas mediadores é a compreensão das ações que devem ser executadas para que o programa traga o texto à tela. $\mathrm{O}$ acesso a informação sobre o tipo de ação deve ser executada nesse ou naquele programa depende da leitura de palavras e ícones. Assim, ainda que não seja condição suficiente para o domínio do agente mediador, o letramento alfabético é indispensável para o letramento eletrônico (BUZATO, 2001, p. 85-86).

Apesar de possuírem certo letramento eletrônico, corroborado pelo número de acessos a INTERNET, a maioria dos estudantes (74\%) ainda não havia tido contato com AVEA (Figura 3). Possivelmente, esta resposta esteja associada ao fato de quê à disciplina seja oferecida no terceiro semestre do curso de Zootecnia. Porém, outro fato a ser considerado estaria relacionado à formação dos professores quanto à utilização do ambiente virtual de ensino aprendizagem na mediação das suas atividades didáticas. Quanto a capacitação docente para o emprego de AVEA, Barin et al. (2012) colocam que:

"A formação de professores para o uso das TIC encontra uma complexa rede de possibilidades e necessidades que vai sendo tecida a partir das novas tecnologias, que evoluem constantemente na sociedade da informação; dos sujeitos da aprendizagem, normalmente familiarizados com esse avanço tecnológico de forma mais afinca que o próprio professor; da leitura crítica da sociedade e do papel da escola na formação do cidadão. Assim o desafio que se apresenta é a formação inicial e continuada de professores capaz de promover para além de conhecimentos específicos de natureza científica e pedagógica, a autonomia, criatividade, reflexão crítica, espírito colaborativo, empreendedorismo, autonomia e a fluência tecnológica".

Quanto uso específico do AVEA na disciplina de Climatologia Zootécnica (Tabela 1, pergunta $\mathrm{n}^{\circ} 1$ ), a maioria dos estudantes acreditam que seu emprego favorece o processo ensino-aprendizado. Dentre as justificativas para as respostas positivas encontram-se com freqüência respostas como "ferramenta auxiliar" e "incrementa a relação professor-aluno". Esse incremento na intera-

Tabela 1- Avaliação do uso do Ambiente Virtual de Ensino Aprendizagem no processo de ensinoaprendizagem da disciplina Climatologia Zootécnica.

\begin{tabular}{|l|c|c|}
\hline \multicolumn{1}{|c|}{ Perguntas } & \multicolumn{2}{|c|}{ Respostas (\%) } \\
\cline { 2 - 3 } & Sim & Não \\
\hline $\begin{array}{l}\text { 1. Você acredita que o Ambiente Virtual de Ensino Aprendizagem } \\
\text { pode ser adotado na disciplina de Climatologia Zootécnica para } \\
\text { favorecer o aprendizado? Justifique sua resposta. }\end{array}$ & 92,9 & 7,1 \\
\hline $\begin{array}{l}\text { 2. Você acredita que o Ambiente Virtual de Ensino Aprendizagem } \\
\text { possa ser adotado nas demais disciplinas da Zootecnia, diminuindo } \\
\text { assim a carga horária presencial dos alunos? Justifique sua resposta. }\end{array}$ & 21,4 & 78,6 \\
\hline $\begin{array}{l}\text { 3. Você acredita que a educação tradicional, com alunos enfileirados } \\
\text { escutando a transmissão de conteúdos, deve ser mantida na } \\
\text { Universidade? Justifique sua resposta }\end{array}$ & $66,7 *$ & 19,1 \\
\hline
\end{tabular}


tividade é descrita por Fruet e De Bastos (2010):

"Essa comunicação no âmbito do ensinar-aprender pode ocorrer de duas maneiras: assíncrona e síncrona. A primeira não implica uma interação simultânea. Percebe-se que essa é o modo predominante, uma vez que o aluno, ao ler um material disponibilizado pelo professor na tela do computador ou ao realizar uma atividade agendada pelo docente no AVEA, e o professor, ao ler a respectiva resposta e enviar um feedback, estarão interagindo assincronamente. $\mathrm{O}$ correio eletrônico (mensagens), o fórum e o wiki são exemplos de ferramentas que possibilitam comunicação assíncrona. Já a segunda maneira, síncrona, caracteriza-se por uma interação simultânea, que pode acontecer, por exemplo, por meio da ferramenta chat" (FRUET; DE BASTOS, 2010, p. 83).

A importância do AVEA em ser uma ferramenta pedagógica e interativa é ressaltada por Cordenonsi e Bernardi (2010):

"Muito mais que um mero artefato tecnológico, um AVEA passa a ser um instrumento pedagógico. Em última análise, o próprio ambiente pode ser considerado objeto de aprendizagem; mais complexo e muito mais interativo que a maioria dos objetos desenvolvidos, mas, em suma, um objeto que é utilizado como meio de comunicação e de suporte para as atividades desenvolvidas pelos alunos e pelos professores. Essas atividades podem ser traduzidas desde o simples apoio aos encontros presenciais até como, potencialmente, único meio de comunicação e interação entre comunidades puramente virtuais" (CORDENONSI; BERNARDI, 2010. p. 257-258).

As respostas negativas associadas à pergunta $\mathrm{n}^{\circ} 1$ foram de $7,6 \%$ (Tabela 1 ) e estiveram relacionada a dificuldade encontrada pelo fato ser o primeiro acesso a plataforma. Mesmo assim, esse percentual pode ser considerado baixo, visto que $74 \%$ dos (Figura 3) ainda não haviam tido contato prévio com o ambiente virtual de ensino aprendizagem.

Quanto à adoção do Ambiente Virtual de Ensino Aprendizagem em outras disciplinas (Tabela 1 , pergunta $n^{\circ} 2$ ) somente $21,4 \%$ dos estudantes concordaram em quanto que $78,6 \%$ discordaram da sua utilização. Essa resposta deve ser analisada com cautela, visto que a pergunta $\mathrm{n}^{\circ} 2$ incluía tanto a adoção ambiente virtual de ensino aprendizagem quanto à redução da carga horária presencial. Justamente, neste fato é que residiu à justificativa da maioria ter escolhido a opção "Não". Pelas justificativas apresentadas, ressaltam-se as posições de "complemento" e "sem redução da carga horária". Tal fato denota que os estudantes consideram a utilização do AVEA como um complemento/ferramenta auxiliar as atividades presenciais. Acrescenta-se ainda conjuntura da grade curricular (10 semestres) em relação ao semestre da disciplina ( $3^{\circ}$ semestre). Possivelmente, os estudantes ainda não tenham visão clara das disciplinas a serem cursadas e aplicação do Ambiente Virtual de Ensino Aprendizagem nas mesmas. Talvez, esta circunstância tenha colaborado para o acréscimo das respostas negativas.

A pergunta $n^{\circ} 3$ (Tabela 1) confrontava, basicamente, o ensino presencial e a distância. Observa-se que $66,7 \%$ dos estudantes foram favoráveis ao "ensino tradicional", caracterizado pelo "professor/ator" e "estudante/espectadores", sendo $19,1 \%$ foram contrários a sua manutenção. Houve respostas bastante conflitantes, sendo duas transcritas a seguir:

- Estudante 1: "Sim. Não acredito haver uma forma melhor no método de transmissão do conhecimento se não pelo contato direto entre aluno e professor, possibilitando o dialogo pessoal e objetivo".

- Estudante 2: "Não, pois a universidade tem por objetivo nos mostrar como será o mundo lá fora e a educação tradicional encontra-se quase ultrapassada para os interesses do homem moderno, queremos sempre mais e futuramente sentiremos a necessidade de mudar os métodos de ensino, e hora de investir mais em educação.".

Acrescenta-se que a resposta do "Estudante 2" vai o encontro das constatações de Barin et al. (2012) de que "Em relação a este questionamento, os estudantes relatam que na maioria das vezes a tecnologia utilizada é o Datashow, mas que, no entanto ao invés de agregar informações o uso inadequado das TIC, torna a aula ainda mais cansativa. Os mesmos demonstram preocupação com sua própria conduta enquanto futuros professores, pois temem repetir àquilo que thes foi proporcionado". Assim, observa-se que alguns estudantes demonstram a preocupação de ter contato com novas formas aprender.

Ressalta-se que $14,2 \%$ das respostas não puderem ser classificadas nas duas opções colocadas (Tabela 1 , pergunta $n^{\circ} 3$ ). Uma resposta escolhida para caracterizar essa opinião foi:

- Estudante 3: "Acredito na educação tradicional, porém renovada, onde os alunos estejam em aula e tenham bons professores com metodologias novas e atrativas aos alunos".

Neste cenário de novas formas de aprender, colocado pelo estudante 2 de "mudar os métodos de ensino" e pelo estudante 3 de "metodologias 
novas", Martinsi (2008) coloca que "há necessidade de se oferecer alternativas para que o aluno possa representar e expressar o conhecimento e, assim, aprender a orientar-se e a encontrar referências que permitam, de forma significativa, analisar, selecionar, interpretar e fazer uso da avalanche de informações que recebe diariamente. Repensar a educação, considerando a cultura e os meios de expressão que a permeiam, tem a função de potencializar a interpretação do que está sendo aprendido a partir de diferentes pontos de vista, favorecendo a tomada de consciência dos alunos sobre si mesmos e sobre o mundo do qual fazem parte".

O professor deve desenvolver competências e habilidades para trabalhar com recursos tecnológicos que contextualizem suas atividades didáticas, utilizando-as como mais uma ferramenta pedagógica enriquecedora do texto e do contexto trabalhados (HAMZE, 2010). Quanto a modificação da prática docente e uso de recursos tecnológicos, ressalta-se a seguinte colocação:

"A simples inserção de suportes tecnológicos na sala de aula não representa uma contribuição realmente transformadora, constituindo-se estes, em muitos casos, em meros acessórios ou em objetos de propaganda institucionais. Novas tecnologias e aparelhagens sofisticadas não são garantia de desempenho acadêmico, seja qual for o instrumento de avaliação utilizado. A verdadeira transformação está na mudança metodológica e na avaliação contínua desses métodos pelos professores. Dentro desse contexto, as ferramentas computacionais podem ser utilizadas de forma realmente efetiva. O investimento tecnológico só se justifica caso o objetivo final da implementação do sistema seja plenamente satisfatório, ou seja, se ocorrer à efetiva aprendizagem do educando (CORDENONSI; BERNARDI, 2010, p. 253-254)."

Analise das respostas sugere que um comportamento bastante diferenciado entre os estudantes quanto ao processo de ensino-aprendizagem, enquanto que o primeiro se situaria em perfil mais passivo, o segundo denota ser favorável a "novas propostas". Estas respostas também são um indicativo dos desafios a serem enfrentados pelo docente na adoção de novas propostas para mediar o processo de ensino-aprendizagem. Por um lado, pode haver estudantes que tenham certa desconfiança quanto mudar para o "novo", e por outro, a mudança pode não ser "tão radical" como aquela que era esperada por alguns estudantes. Acrescenta-se ainda a mudança relativa nova postura docente a ser aplicada, a qual pode ser um grande desafio a ser enfrentado, Pois Mion et al. (1999) colocam que "..., por meio do processo reflexivo muda-se a concepção de docente, uma vez que, investigando a prática educacional, torna-se investigador ativo e/ ou educador-educando" (MION et al. 1999, p. 203-204). Essa mudança de concepção docente é um passo imprescindível para a adoção de novas práticas pedagógicas, sendo um grande desafio a ser vencido, pois exigirá a apropriação de novas habilidades, notadamente na TIC. Kenski (2010) acrescenta que educar para a inovação e a mudança, significa planejar e implantar propostas dinâmicas de aprendizagem, em que se possam exercer e desenvolver concepções sócio históricas da educação nos aspectos cognitivos, ético, político, cientifico, cultural, lúdico e estético em toda a sua plenitude, e assim, garantir a formação de pessoas para o exercício da cidadania e do trabalho com liberdade e criatividade.

\section{CONCLUSÕES}

Em função dos resultados obtidos conclui-se que os estudantes: (i) a maioria (74\%) não havia utilizado ambiente virtual de ensino aprendizagem nas disciplinas cursadas, (ii) acessam diariamente a INTERNET, indicando que os estudantes possuem letramento eletrônico adequado para desenvolver atividades no ambiente virtual de ensino aprendizagem; (iii) apresentam ótima aceitabilidade para a execução de atividade a distância, pois efetivamente executaram a atividade proposta, com um índice de postagem de $77 \%$ e (iv) acreditam que o ambiente virtual de ensino aprendizagem pode ser adotado na disciplina de Climatologia Zootécnica para favorecer o aprendizado, (v) acreditam a educação tradicional deve ser mantida e consideram que as atividades à distância sejam um complemento muito importante daquelas presenciais.

\section{REFERÊNCIAS BIBLIOGRÁFICAS}

BARIN, Claudia Smaniotto; MÜLLER, Liziany; ELLENSOHN, Ricardo Machado. Construção de significados e interação com, no e pelo computador: estudos problematizados no AVEA Moodle sobre o uso das tecnologias da informação e comunicação. Revista RENOTE, v. 10, n. 1, 2012. Disponível em: http://seer. ufrgs.br/renote/article/view/30881/19234. Acesso em: 20 jan. 2013

BUZATO, Marcelo E1 Khouri. Letramento eletrônico e o uso de computadores no ensino de língua estrangeira: 
contribuições para a formação de professores. 2001. 188 f. Dissertação (Mestrado em Linguística Aplicada) Universidade Estadual de Campinas, Campinas, 2001.

CORDENONSI, André Zanki; BERNARDI, Giliane. Ambientes Virtuais de Ensino-Aprendizagem e Objetos Educacionais: o diálogo mediado por tecnologias na educação superior. Inter-ação, v. 35, p. 253-274, 2010.

FRUET, Fabiane Sarmento Oliveira; DE BASTOS, Fábio da Purificação. Interação mediada por computador: hipermídia educacional nas atividades de estudo a distância. p 81-98, 2010. Disponível em: http:// www.ucs.br/etc/revistas/index.php/conjectura/article/.../326/280. Acesso em: fev. 2013.

HAMZE, Amélia. Linguagem Audiovisual e a Educação. 2010. Disponível em: http://www.educador. brasilescola.com/gestao-educacional/linguagem.htm. Acesso em: 20 jan. 2013.

KENSKI, Vani Moreira. Educação e tecnologias o novo ritmo da informação. CAMPINAS: PAPIRUS, 6 ed. 2010 , v.1. 141 p. 2010

MARTINSI, Maria Cecília. Situando o uso da mídia em contextos educacionais. 2008. Disponível em: http:// midiasnaeducacao-joanirse.blogspot.com/2008/12/ situando-o-uso-da-mdia-em-contextos.html Acesso: jan $/ 2013$

MION, Rejane Aurora, ANGOTTI, José André Peres; De BASTOS, Fábio da Purificação. Construindo a formação problematizadora e dialógica do educador. Revista Olhar de professor, v. 2, n. 2, p. 195-206, 1999.

MORAES, Carolina Roberta, VARELA, Simone. A motivação do aluno durante o processo de ensino-aprendizagem. 2006. Disponível em: http://web.unifil. br/docs/revista_eletronica/educacao/Artigo_06.pdf. Acesso em: dez 2012.

MÜLLER, Liziany; BANDEIRA, Andrieli Hedlun; ALVES, Bruna Mendonça; BARIN, Claudia Smaniotto; MALLMANN, Elena Maria. Recursos das tecnologias de informação e comunicação mediando o ensinoaprendizagem e configurando ecologias cognitivas de estudantes do Centro de Ciências Rurais. Revista RENOTE, v. 9, p. 1-10, 2011. Disponível em: http:// seer.ufrgs.br/renote/article/view/25118. Acesso em: 20 jan. 2013

PASSOS, Paula Caroline Schifino Jardim; BEHAR, Patricia Alejandra. Interação e Interatividade atra- vés das interfaces de materiais educacionais digitais. Revista RENOTE, v.9, n.1, 2011. Disponível em: http:// seer.ufrgs.br/renote/article/download/21886/12695. Acesso em: fev. 2013.

RODRIGUES, Iracema Stancati. A mudança da prática pedagógica do modelo presencial para o modelo de educação à distância sob as óticas da teoria da atividade e da metodologia inovadora. 2005. Disponível em: http:// www.abed.org.br/congresso2005/por/pdf/221tcc5.pdf. Acesso em: 14 jan. 2012.

VASCONCELOS, Maria Helena Schneid; TOGNI, Ana Cecília. Aprendendo estatística no ensino médio e no curso técnico agrícola em agropecuária utilizando o objeto de aprendizagem estatística net. . Saber Acadêmico - ${ }^{\circ}{ }^{\circ} 11$ - jun. 2011. 